\title{
Current understanding of narcissism and narcissistic personality disorder
}

\author{
Jessica Yakeley
}

\begin{abstract}
SUMMARY
This article reviews historical contributions to the conceptualisation of narcissism and narcissistic personality disorder (NPD), including its evolution as a clinical diagnosis within the DSM classification of mental disorders. It discusses the epidemiology and aetiology of NPD, noting that empirical studies of both are limited. The challenges of managing patients with prominent narcissistic traits are presented, and the psychological therapies specifically designed for the treatment of patients with NPD are summarised.
\end{abstract}

\section{LEARNING OBJECTIVES}

- Understand different models of narcissism

- Understand the epidemiology, comorbidity and theories of aetiology of NPD

- Know how to manage and treat patients with pathological narcissism and NPD

\section{DECLARATION OF INTEREST}

None.

The legend of Narcissus in Greek mythology, from which the term narcissism derives, has become one of the most prototypical myths of modern times. The most popular version of the story is by Ovid in his work Metamorphoses, in which Echo, a mountain nymph, encounters Narcissus, a beautiful young man, who rejects her advances. Heartbroken, Echo lives out her life in desolation until only an echo of her voice remains. Nemesis, the goddess of revenge, punishes Narcissus by luring him to a pool of water, in which he catches an image of himself and, not realising it is his own reflection, falls in love with it. The more he gazes, the more infatuated he becomes. Eventually he realises that his love can never be reciprocated and, condemned to the same fate that he had inflicted on Echo, he remains in despair, fixated by his image until death; Echo, at his side, repeats his last words.

Narcissism has become a defining feature of the modern era: interest in the concept has captured the imagination of the public, media and literature. In the 1970s the American journalist Tom Wolfe coined the phrase 'the "Me" decade' to describe the rise in celebration of the self (Wolfe 1976) and the American historian and social critic Christopher
Lasch published The Culture of Narcissism, in which he explores the rise of narcissistic entitlement and decadence (Lasch 1979). These popularised texts have been paralleled by a growing body of academic interest and empirical research, particularly in the fields of psychology, social science and cultural studies. Within psychiatry, the concept of narcissism has evolved from early psychoanalytic theorising to its official inclusion as a personality disorder in psychiatric nomenclature.

\section{Historical review of the concept of narcissism}

Psychoanalytic models of narcissism

Havelock Ellis was the first theoretician to use the Narcissus myth to describe narcissism as a clinical entity, in his description of states of intense autoerotism or preoccupation with one's own sexual body (Ellis 1898). Psychoanalysts subsequently elaborated the construct of narcissism as a personality characteristic of vanity and self-love that is not exclusively sexual, nor confined to the realm of pathology, but a normal part of human development. Otto Rank (1911) wrote the first psychoanalytic paper focusing on narcissism, and this was followed by the publication of Freud's now classic text On Narcissism (Freud 1914). These papers highlighted the defensive function of narcissism in protecting the individual from feelings of low self-worth and selfesteem, as well as conceptualising narcissism as a dimensional psychological state that ranged from normal to pathological, forerunning the ideas of more contemporary personality trait theorists (Levy 2011). Later psychoanalysts expanded on the idea of a narcissistic personality type, for example in Wilhelm Reich's 'phallic-narcissistic character' (Reich 1933), Karen Horney's subdivisions of 'aggressive-expansive', 'perfectionist' and 'arrogant-vindictive' (Horney 1939) and Donald Winnicott's notions of the true and false self (Winnicott 1960).

However, the respective (and conflicting) theories of the psychoanalysts Heinz Kohut and Otto Kernberg might be said to have exerted the most influence on modern conceptualisations of narcissism and on shaping the construct of narcissistic personality disorder (NPD). Kohut's self-psychology
Jessica Yakeley is a consultant psychiatrist in forensic psychotherapy, Director of the Portman Clinic, and Director of Medical Education at the Tavistock and Portman NHS Foundation Trust, London. She is also Editor of Psychoanalytic Psychotherapy and a Fellow of the British Psychoanalytical Society Correspondence Dr Jessica Yakeley, Portman Clinic, 8 Fitzjohns Avenue, London NW3 5NA, UK. Email: jyakeley@tavi-port.nhs.uk

Copyright and usage (C) The Royal College of Psychiatrists 2018 
approach (Kohut 1971) offers the 'deficit model' of narcissism, which asserts that pathological narcissism originates in childhood as a result of the failure of parents to empathise with their child. The normal integration of the 'grandiose self' and 'idealised parental imago' does not occur and grandiose omnipotence emerges as a defence against fragmentation of the self. Narcissistic individuals are prone to experiencing emptiness and depression in response to narcissistic injury. By contrast, Kernberg's object relations approach (Kernberg 1984) emphasises aggression and conflict in the psychological development of narcissism, focusing on the patient's aggression towards and envy of others. In this 'conflict model', early childhood experiences of cold, indifferent or aggressive parental figures push the child to develop feelings of specialness as a retreat. These feelings evolve into a pathological grandiose self-structure, which defends against the child's rage at his inability to internalise good objects. In pathologically narcissistic individuals, primitive defence mechanisms of idealisation, denigration and splitting predominate, the capacity for sadness, guilt and mourning is lacking, and the main affects are shame, envy and aggression.

\section{Social and personality models of narcissism}

These psychoanalytic theories, based on clinical work with narcissistic patients, were paralleled by developments in social critical theory. Following the sociologist and philosopher Theodore Adorno's (1968) proposition that narcissism was a result of the collective ego's defensive response to industrialisation and the changing economic and social structure of society, writers such as Wolfe and Lasch documented the rise of the cult of the individual, self-expression, self-admiration and materialism as key to economic prosperity, happiness and success, away from traditional American societal values anchored in family and community. More recently, accumulated empirical research findings from studies that document rising rates of narcissism in American college students between 1979 and 2006 revealed an 'epidemic of narcissism' within American society (Twenge 2009). Cultural studies have suggested that the USA is seen as a more narcissistic society, in which individualism, professional success, fame and material wealth are celebrated, in contrast to Eastern cultures in Asia and the Middle East, which promote collectivism and more shared parenting practices and where self-reports of narcissistic traits have been shown to being lower than in Western countries such as the USA (Foster 2003).
The field of social-personality psychology and its research on assessment and factor analysis has increasingly influenced contemporary theories regarding narcissism, such as its links to shame, victimhood and aggression. There is now a large empirical literature in the field that conceptualises narcissism as a normative personality trait, which can be adaptive and maladaptive. Most of this research has relied on the Narcissistic Personality Inventory (Raskin 1979), the instrument most frequently used to measure narcissism, although it has been criticised for assessing adaptive components such as self-esteem, well-being and leadership at the same time as maladaptive features such as grandiosity and entitlement.

Although the cognitive-behavioural literature on narcissism is relatively sparse in comparison with that on psychoanalytic and psychodynamic approaches, theoreticians and clinicians within the cognitive-behavioural tradition have more recently applied this approach to the study of NPD, in their emphasis on the social learning of core beliefs or self-schemas. Theodore Millon's (1981) social learning perspective proposes that children learn about themselves and others from their parents' behaviour, and in narcissistic individuals, beliefs about specialness and entitlement are thought to stem from early parental overindulgence. Others have pointed to parental abuse and neglect as instrumental in the development of pathological narcissism. Beck described dysfunctional core beliefs or schemas, stemming from early experiences of adverse parenting, associated with NPD that lead the person to be self-indulgent, demanding and aggressive, but also highlighted how these individuals often presented with symptoms of depression (Beck 1990). Cognitive theorists such as Jeffrey Young (Young 2003) have expanded Beck \& Freeman's (1990) original theories of core distorted beliefs and dysfunctional schemas via integration with interpersonal and gestalt perspectives and a particular focus on the role of negative early experiences and affects in the aetiology and treatment of NPD.

\section{Narcissism, narcissistic personality disorder and the DSM}

The widespread use of the concept of pathological narcissism as a distinct personality type by clinicians influenced by psychoanalysts such as Kernberg and Kohut, as well as psychologists such as Millon, led to the introduction of narcissistic personality disorder into the third edition of the DSM (DSM-III) in 1980 (American Psychiatric Association 1980). The NPD construct was further refined and modified as it evolved through 
DSM-III-R (1987) and DSM-IV (1994) on the basis of the empirical findings of an increasing number of psychological studies identifying narcissism as a personality trait. However, these shifts in the diagnostic criteria for the disorder were criticised for losing some of the more dynamic variables present in its phenomenological manifestations. Authors such as Cain et al (2008) noted that DSM-IV predominantly focused on the disorder's grandiose features and did not adequately capture the underlying vulnerability that is evident in many narcissistic individuals.

Inconsistencies in the conceptualisation of narcissism, including differences in describing its nature (normal, pathological), phenotype (grandiosity, vulnerability), expression (overt, covert) and structure (category, dimension, prototype), were reflected in the limited descriptions of these areas in the DSMIV definition of NPD (Pincus 2010). Another criticism levelled at NPD as defined by the DSM is that it is one of the rarer personality disorders found in community and clinical samples, despite the widespread clinical observation of a much higher prevalence of problematic narcissistic traits in patients with personality difficulties. These shortcomings were to be ameliorated in a new model of personality disorder as a categorical-dimensional hybrid, which was intended to become the official approach to the diagnosis of all personality pathology and disorders in DSM-5 (American Psychiatric Association, 2013). This model is based on the assessment of core aspects of personality functioning and pathological personality traits and has received much support from researchers and clinicians in the personality disorder field. One of the main goals of the new classification in DSM5 was to increase the validity of mental disorder diagnoses by incorporating dimensional assessment, which is particularly relevant to NPD, given that narcissism occurs on a spectrum of severity from normal to pathological. However, disagreements within the personality disorder research community, as well as the American Psychiatric Association, resulted in this new model of personality disorder not being adopted by DSM- 5 , although it has been placed in Section III of the manual ('Emerging measures and models') as an area for future study (Skodol 2014). The diagnostic criteria for NPD in DSM-5 (American Psychiatric Association 2013) therefore remain identical to those in DSM-IV (Box 1).

\section{Diagnosis of narcissistic personality disorder}

The recent controversy over psychiatrists 'diagnosing' the current President of the USA, Donald
BOX 1 DSM-5 criteria for NPD

$\begin{array}{ll}\text { - Grandiosity and self-importance } & \text { - Manipulates and exploits others } \\ \text { - Persistent fantasies of success, power, } & \text { - Lack of empathy } \\ \text { attractiveness, intellectual superiority or ideal } & \text { - Believes others are envious of him/her and } \\ \text { love } & \text { envy of others } \\ \text { - Sense of superiority and specialness } & - \text { Arrogant and contemptuous attitudes and } \\ \text { - Wish to be admired } & \text { behaviours } \\ \text { - Strong sense of entitlement } & \end{array}$

Trump, with NPD led the American Psychiatric Association to issue a warning to its members to stop 'psychoanalysing' him, because it breached the organisation's code of ethics by offering a professional opinion without conducting an examination and being granted proper authorisation to make such a statement (Oquendo 2016), and it exemplifies some of the pitfalls of diagnosing personality disorders. The conceptual confusion in defining NPD may render this disorder particularly prone to being attributed to individuals, especially those in the public limelight, without taking a full history and examination, failing to confirm functional impairment or diagnosing on the basis of a single trait.

The diagnostic criteria for NPD in DSM-5, as noted above, are focused on characteristics of grandiosity and entitlement rather than more vulnerable manifestations of the disorder. It is now generally accepted that at least two subtypes or phenotypic presentations of pathological narcissism can be differentiated: grandiose or overt narcissism and vulnerable or covert narcissism (Cain 2008; Pincus 2014). People with the former subtype may appear arrogant, pretentious, dominant, self-assured, exhibitionist or aggressive, whereas people with the latter may present as overly sensitive, insecure, defensive and anxious about an underlying sense of shame and inadequacy. These two opposing presentations have been well described in the psychoanalytic literature, exemplified by Rosenfeld's original description of 'thick-skinned' and 'thinskinned' narcissism (Rosenfeld 1987), ideas elaborated by Bateman (1998) and Britton (2003), who emphasise how the coexistence of thick- and thinskinned narcissistic aspects in the same individual may be understood as the former defending against the latter, and raise some of the technical challenges of how to address these in treatment, as described later in this article.

These theories highlight how the narcissistic person's overt attitudes and behaviours may differ markedly from their inner subjective experience, where grandiosity may conceal an underlying sense of impotence, shame and inadequacy and, conversely, 
manifest shyness and reticence may shield a secret sense of importance. Moreover, healthy narcissistic functioning may coexist with pathological narcissism and vary according to context and interpersonal relationships. Nevertheless, both individuals with grandiose and those with vulnerable narcissism share a preoccupation with satisfying their own needs at the expense of the consideration of others: pathological narcissism is defined by a fragility in self-regulation, self-esteem and sense of agency, accompanied by self-protective reactivity and emotional dysregulation. Grandiose and self-serving behaviours may be understood as enhancing an underlying depleted sense of self and are part of a self-regulatory spectrum of narcissistic personality functioning (Ronningstam 2014).

Confusion may arise, however, in the differential diagnosis of NPD from antisocial personality disorder and psychopathy. The overlap between conceptualisations of pathological narcissism and psychopathy is well-documented. In his seminal work on the characteristics of the psychopath, Cleckley (1941) includes several aspects of narcissism, such as a sense of entitlement, ego-centricity and lack of empathy, which are reflected in the Psychopathy Checklist - Revised (PCL-R; Hare 2003), the most commonly used risk-assessment instrument measuring psychopathy in forensic settings. Kernberg proposes that psychopathy is a malignant form of narcissism characterised by NPD, antisocial features, paranoid traits and sadism (Kernberg 1992). However, neither malignant narcissism nor psychopathy is recognised as a discrete diagnostic category in the DSM or ICD classifications of mental disorders. Features of psychopathy are subsumed within the broader DSM category of antisocial personality disorder, which is the most common personality disorder that is comorbid with NPD. Patients with NPD who also have features of antisocial personality disorder and psychopathy may present a higher risk to others and may need to be managed within forensic services.

\section{Epidemiology of narcissistic personality disorder}

Most of the epidemiological research on NPD has been conducted using clinical samples, and studies measuring the prevalence of NPD in the general population are lacking. Community studies of the prevalence of personality disorders have been hindered by their small sample sizes and their confinement to specific geographical areas such as individual cities, limiting statistical analysis of the sociodemographics of NPD. A systematic review of studies reporting the prevalence of NPD in adult non-clinical samples found seven studies that used structured or semi-structured interviews to assess for personality disorder: the overall mean prevalence of NPD was $1.2 \%$ and the range $0-6.2 \%$ (Dhawan 2010). The most recent and comprehensive of these studies is the Wave 2 National Epidemiologic Survey on Alcoholism and Related Conditions (NESARC). This was a large, nationally representative epidemiological survey of 34093 civilians in the USA carried out between 2004 and 2005, which assessed alcohol and drug use, psychiatric disorders, and the risk factors associated with and the consequences of alcohol and drug use, by conducting face-to-face interviews (Hasin 2015). This survey showed an overall prevalence of NPD of $6.2 \%$, with rates higher for men $(7.7 \%)$ than for women (4.8\%). NPD was also significantly more common in Black men and women and Hispanic women, younger adults and people who were separated, divorced, widowed or never married. High rates of co-occurring substance use, mood, anxiety and other personality disorders were observed (Stinson 2008). The prevalence of NPD in the UK population is not known, as it has not been specifically measured in large-scale studies of the prevalence of mental disorders here, such as the British psychiatric morbidity surveys (Jenkins 2003).

NPD has a relatively low prevalence in most clinical samples of patients with mental or personality disorders (Zimmerman 2005; Katerud 2007). Depression and dysthymia are the most commonly found comorbid mental illnesses in NPD. Symptoms of NPD, in particular grandiosity and inflated selfesteem, may be seen in the manic phase of bipolar disorder, and it is not clear whether the comorbidity between the two disorders is a reflection of shared vulnerability or is just an overlap of diagnostic criteria. NPD is a relatively common comorbid disorder in drug and substance use disorders and has also been found to be comorbid with anxiety disorders, anorexia nervosa and post-traumatic stress disorder. People with NPD are at increased risk of suicide (Ronningstam 1996). The DSM-5 personality disorders most frequently found to be comorbid with NPD are histrionic personality disorder and antisocial personality disorder (Widiger 1998), which may pose difficulties in differential diagnosis. The overall relatively low prevalence rates of NPD reported in samples from both clinical settings and the general population may in part be due to the narrow concept identified by the DSM-5 diagnosis, which does not capture the more vulnerable aspects of pathological narcissism.

\section{Aetiology of pathological narcissism and narcissistic personality disorder}

There is an extensive and rich literature regarding aetiological theories of narcissism, predominantly 
from psychoanalytic and psychodynamic perspectives, but more recently from social learning theory and from attachment research. As described above, these theories have been informed by clinical practice and treatment for narcissistic patients and it is only in the past 15 years or so that they have been put to empirical testing. Most of these recent studies have primarily focused on parental behaviour, and although there are differences in measures of narcissism and parenting style, ages of children studied and nationality of participants, all converge to support psychodynamic and learning theories in showing that dysfunctional parenting is significantly associated with the development of pathological narcissism in adulthood (for a comprehensive review of these studies see Horton 2011). Interestingly, although studies suggest that parental indulgence is associated with both grandiose narcissism and vulnerable narcissism, parental coldness and emotional control of the child are more likely to be associated with vulnerable narcissism.

Emerging evidence that very early disturbances in the relationship between the child and primary caregiver may be linked to the development of narcissism arises from attachment research, in which studies have reported an association between both dismissing and preoccupied attachment styles as measured on the Adult Attachment Interview and pathological narcissism and NPD in adults (Rosenstein 1996; Dickinson 2003; Smolewska 2005; Otway 2006; BakermansKranenburg 2009; Miller 2010; Diamond 2014; Fossati 2014). These contradictory attachment patterns (i.e. dismissing and anxious/preoccupied) have been linked respectively to the mental states of grandiosity and vulnerability found in NPD (Cain 2008; Meyers 2011).

Very few studies have looked at a genetic basis for NPD. One such, assessing cluster B personality disorders in 1386 Norwegian twin pairs between the ages of 19 and 35, estimated a heritability of $24 \%$ for NPD compared with $38 \%$ for antisocial personality disorder, 35\% for borderline personality disorder and 31\% for histrionic personality disorder (Torgersen 2008). In another, 144 community participants belonging to 36 biological family groups completed the Narcissistic Personality Inventory and a measure of parenting style. Results indicated a significant father-daughter correlation for levels of narcissism, but close to zero correlations for other parent-offspring dyads. The authors cautiously interpreted this as evidence for a possible genetic basis, including X-chromosome involvement, for narcissistic personality traits, with parenting style contributing relatively little (Miles 2014).

\section{Challenges in the management and treatment of narcissistic personality disorder}

Individuals with symptoms of NPD may present to primary care services with a variety of complaints, although the diagnosis is often missed at this stage. They seek treatment for various reasons, but a common theme is that their experience of life, and in particular of their relationships, does not live up to their elevated standards and expectations. They often have little insight that their difficulties may be due to problematic personality traits and instead externalise their problems, projecting them onto others. A sense of victimhood or entitlement is common, with the patient blaming others for treating them badly or criticising them for faults that they see in other people but deny in themselves. They may also present in crisis, describing difficulties with or complaints from family, friends or employers, or legal sanctions that they do not accept; or they may be referred to mental health services because of comorbid mental conditions, such as a depressive disorder, or suicidality. Other manifest difficulties include social isolation, sexual dysfunction, irritability and aggression, and an increasing reliance on drugs and/or alcohol to elevate mood. Some report feelings of emptiness, dysphoria and despair; in others, feelings of shame, humiliation and worthlessness may predominate, particularly in relation to events such as the break-up of a relationship or loss of their job.

The most common entry point for patients with NPD to psychological therapy services in the UK is through the Improving Access to Psychological Therapies (IAPT) programme, where again, the disorder may not be immediately recognised. If the diagnosis is made, patients often reject it as it challenges their sense of specialness and/or may accentuate feelings of low self-worth, shame and humiliation. Patients are rarely referred to secondary mental health services on account of a diagnosis of NPD, but they may present because of comorbid mental illness such as anxiety or depressive disorders.

People with NPD are often difficult to engage in treatment, which underscores the importance of gradually building a therapeutic alliance, with mutually agreed goals within a clearly outlined treatment frame in the initial stages of any treatment offered. If a therapeutic process can be initiated, frequent ruptures in the therapeutic relationship should be anticipated, often precipitated by the patient feeling criticised or unfairly treated by the clinician. The patient may also resent the perceived power or expertise of the clinician and reject any treatment offered. Alternatively, narcissistic 
individuals may wish to please the therapist and be their favourite patient; such individuals are often skilled at learning what is expected of them in therapy and may report improvement without evidence of any real therapeutic change.

As in some individuals with antisocial or histrionic personality disorder, feelings of shame and humiliation arising in relation to perceived slights and lack of respect from others may be a central conflict for people with NPD and may cause particular challenges within the therapeutic relationship. The offer of therapeutic help may in itself precipitate feelings of shame if the individual equates weakness and vulnerability with being a patient. Such feelings of vulnerability may be experienced as intolerable and may be defended against by projection, grandiosity and omnipotence within the relationship between patient and therapist, so that the latter is the one who feels shameful and inadequate. Such countertransferential responses in the therapist may be understood psychoanalytically as an unconscious communication from the patient to the therapist of the former's problem in receiving and using help, via the process of projective identification (Klein 1946) in which the therapist is made to feel feelings that the patient disowns. Returning to the myth of Narcissus and Echo, this illustrates the idea of how Narcissus thwarts a relationship by turning away from the desire for connection, leaving a rejected and vulnerable part of himself reflected in the character of Echo. Similarly, in trying to make a connection with a narcissistic patient, the professional may need to unconsciously bear the echo of the patient's narcissistic psychopathology and tolerate holding the rejected and vulnerable part of the patient's self.

These treatment challenges highlight the complex countertransferential responses that may be provoked in clinicians, such as frustration, anger or therapeutic nihilism, or, on the contrary, feelings of specialness and therapeutic expertise. This underscores the importance of regular clinical supervision, reflective practice, case discussion groups or Balint groups, regardless of treatment modality, in which the clinician's feelings can be safely explored to gain insight into the patient's psychopathology and interpersonal difficulties and the way they affect the therapeutic relationship. It should be recognised, however, that feelings of shame and resentment in therapists and other professionals in contact with narcissistic patients may make it particularly difficult for them to seek or effectively use supervision, with the risk that unhelpful and even punitive countertransferential responses by clinicians, for example refusing access to treatment, may go unchecked (Box 2).
BOX 2 Case vignette: entitlement and grandiosity

Marco, a middle-aged man, was referred to mental health services following an overdose taken in the context of the break-up of a relationship. He was assessed by a female higher trainee in general adult psychiatry, who recommended that he be referred to the psychological therapies service for an assessment for dialectical behaviour therapy (DBT). He reported previously receiving several years of intensive psychotherapy in his home country with 'a wellknown analyst'. Following this assessment, he complained that the psychiatrist who had seen him was clearly too young and inexperienced to understand the complexity of his difficulties and demanded to be seen by a more senior clinician. The consultant psychiatrist, an older man, agreed to review him. He noted that Marco probably fulfilled criteria for narcissistic personality disorder, but that it would be counterproductive to discuss this diagnosis with him. Instead, he acknowledged Marco's concerns and explained that, although the female psychiatrist was clearly younger than himself and Marco, nevertheless she was well trained and achieved as good results as any other clinician in the service. Moreover, he confirmed that DBT might be a suitable therapy at this point, as although it was timelimited, it would be more focused, particularly on destructive behaviours such as self-harm, and would give Marco skills to better manage his impulses and emotions, especially in the context of his relationships. He suggested that DBT could build on what Marco had achieved in his previous therapy. Marco subsequently engaged in a DBT programme and, although he frequently complained that the treatment was much more 'superficial' than his previous therapy, he made some gains, particularly in controlling his self-harm and being able to acknowledge chronic feelings of low self-worth.

Box 3 lists some common challenges in the treatment of NPD. Please note all case vignettes in this article are fictitious.

\section{Treatments for narcissistic personality disorder}

There is no evidence that any specific psychopharmacological treatment is effective for NPD, although comorbid mental illnesses such as anxiety, depression and bipolar disorder should be treated in their own right. People with NPD may report being particularly sensitive to the side-effects of medication, particularly those that affect their sexual function or intellectual capacity; they may also resent the idea that they might be dependent on pharmacological interventions. These factors may reduce their adherence to treatment.

The mainstay of treatment for NPD is psychological therapy. A number of specific treatment 


\section{BOX 3 Case vignette: countertransference}

Andrew had recently come to the UK from the USA, where he had sought treatment for depression and had been briefly admitted as an in-patient because of concerns regarding his suicide risk. However, following several incidents in which he became confrontational with other patients and staff on the ward when his demands were not met immediately, he had been discharged with the explanation that he had narcissistic personality disorder and was clearly unable to benefit at the time from treatment. Still feeling wounded and angry on arrival in the UK he again started experiencing suicidal thoughts and was referred for a psychiatric assessment. He was initially seen by a junior trainee in psychiatry, who was unable to complete the assessment as he found it difficult to interrupt the patient's lengthy accounts of being 'disrespected' by others, including members of the psychiatric profession. Believing that a doctor's professional code of conduct meant that he should not feel negative emotions towards patients, the trainee suppressed his anger but was left feeling ashamed that he had not been able to properly assess the patient. Fearing that his supervising consultant would reprimand him for this, he feigned illness on the day of their next scheduled clinical supervision. However, he eventually felt able to talk about this situation in the Balint group for trainee psychiatrists that he attended, where the therapist enabled him to understand his countertransferential reaction to the patient as a projection of the patient's feelings of shame and rejection resonating with the trainee's own doubts regarding his competencies and skills as a psychiatrist in training.

modalities and strategies have been developed and advocated for people with pathological narcissism or NPD, but none have been robustly tested for efficacy, and although there is emerging empirical evidence for their effectiveness, no one modality has been proved superior to any other. However, across these differing approaches, common strategies and techniques have been found to be useful, such as the necessity of building a positive therapeutic alliance (Box 4).

Psychotherapeutic treatments of NPD have been developed from within two main traditions: the psychoanalytic/psychodynamic and the cognitivebehavioural. These two approaches differ by being based on distinct theoretical models, paradigms and frameworks, but they share certain techniques and therapeutic interventions. There is increasing support for a more integrated approach to the treatment of personality disorders, including NPD (Livesley 2012), with the recognition that different modalities and techniques can be used synergistically and in a step-wise fashion for the different presentations and developmental stages of the disorders.

In most of the psychotherapeutic modalities described below, the treatment is one-to-one
BOX 4 Challenges in the treatment of narcissistic personality disorder

- Premature termination of treatment or sudden drop-out

- Sensitivity to developmental life changes (e.g. marriage, childbirth, aging) and sudden life events that can disrupt the treatment alliance

- Rejection of the diagnosis, especially features of grandiosity, entitlement and lack of empathy

- Sensitivity to feeling blamed, criticised and unfairly treated, including by the therapist

- Poor affect tolerance, especially of feelings of shame, humiliation and vulnerability

- Wish to please/impress the therapist or imitation of their views without evidence of therapeutic change

- Seeking therapy after several failed previous treatments

- Suicidal ideation and behaviour

- Secondary gain from symptoms

- Aggressive, antisocial or psychopathic features, which are associated with poorer prognosis

- Negative countertransferential feelings in the treating clinician, which may lead to unhelpful or punitive responses such as excluding the patient from treatment

therapy; however, group therapy may be effective in challenging difficulties related to shame, dependency, self-sufficiency, and contempt for and envy of others, although highly narcissistic individuals may dominate or disrupt groups and compete with the therapist to be group leader (Box 5).

\section{Psychodynamic approaches}

Psychodynamic psychotherapy is grounded in psychoanalytic principles, but it is based on a broader theoretical framework capturing relational, interpersonal, intersubjective and embodied experiences of both the social world and the internal world.

BOX 5 Top tips for assessing and managing individuals with narcissistic personality disorder

- Anticipate being treated as an audience to the patient's performance

- Expect to be drawn into lengthy accounts of the patient's life

- In interviewing the patient, agree at the start how and why you will interrupt

- Anticipate negative responses to perceived criticism - any comment that may be interpreted as disrespectful or generates a feeling of shame or humiliation

- Avoid directly challenging a patient, even when they express very negative attitudes

- Be empathic without colluding with what the patient says

- Reflect on negative countertransference reactions rather than revealing these to the patient 


\section{Transference-focused psychotherapy}

The most prominent psychodynamic psychotherapy that has been specifically designed for the treatment of NPD is transference-focused psychotherapy, developed by Kernberg and his collaborators in the USA (Clarkin 2006). Originally developed for the treatment of borderline personality disorder, transference-focused psychotherapy is based on the principles of psychoanalytic object relations theory and its technique is aimed at the active exploration of the patient's aggression, envy, grandiosity and defensiveness. Interpretations are targeted towards uncovering the negative transference, challenging the patient's pathological grandiose defences, and exploring their sensitivity to shame and humiliation; the therapist's countertransference is used as a tool to understand the patient's projection of unacceptable aspects of themselves. Transference-focused psychotherapy is a manualised one-to-one therapy delivered two or three times a week, and it has been shown in randomised controlled trials to improve symptomatic and reflective functioning in borderline personality disorder (Clarkin 2007). For more narcissistic patients, a less interpretative and more supportive technique is used. There has been growing interest in transference-focused psychotherapy in the UK over the past decade, and it is available in some National Health Service (NHS) psychological therapy services.

\section{Mentalisation-based treatment}

In the UK, mentalisation-based treatment, also originally developed for the treatment of borderline

BOX 6 Case vignette: a disruption of group dynamics

Laura, a socially isolated woman with prominent narcissistic pathology, attended a mentalisation-based treatment group for patients with a range of personality disorders. When other group members spoke, she would frequently lean back in her chair, look bored, close her eyes and not contribute to the ensuing discussion unless it directly related to herself. At other times she would dominate the group discussion, frequently interrupt the therapist and give advice to others about how they should change their behaviour. Another group member eventually complained that Laura was clearly disinterested in what they were saying and that her behaviour was rude and disrespectful. The therapist said that he had noticed that Laura seemed to zone out when others talked and he could see that others might interpret this as rudeness, but he wondered how Laura felt during these personality disorder, has been used in the treatment of other mental disorders (Bateman 2012). This group and individual therapy is based on attachment theory and it integrates psychodynamic, cognitive and relational components. It focuses on enhancing mentalisation - the ability to reflect on one's own and others' states of mind and link these to actions and behaviour Although mentalisation-based treatment has not been systematically studied in relation to NPD, there are a few reports in the literature of mentalisation-based treatment programmes specifically designed to treat the disorder (Cherrier 2013; Lee 2013) and of the use of mentalisation-based treatment or mentalisation techniques with patients with narcissistic traits (Seligman 2007; Rossouw 2015). Both transference-focused psychotherapy and mentalisation-based treatment draw from attachment research in their conceptualisations of the psychopathology of NPD.

\section{Cognitive-behavioural approaches}

Several specific empirically based therapeutic modalities developed for the treatment of personality disorder from within a cognitive-behavioural framework have been modified for patients with narcissistic difficulties or disorder. These include schema-focused therapy, dialectical behaviour therapy and metacognitive interpersonal therapy. Therapists and researchers have adapted Beck's cognitive therapy model (Beck 1990) to treat narcissistic thoughts and behaviours. Cognitive techniques such as cognitive reframing, problem-solving and altering dysfunctional thoughts, coupled with behavioural modification techniques such as impulse control, maintaining eye contact and reducing grandiosity, have been demonstrated in narcissistic patients to strengthen the therapeutic alliance and increase adherence to therapy and therapeutic goals (Cukrowicz 2011). moments and whether she was even aware of her behaviour. Laura said she wasn't sure that she was bored - she just automatically 'switched off' sometimes, especially when people spoke too fast or loudly and went 'on and on about their problems'. What gradually became clearer and could be talked about more openly over several sessions was why Laura retreated and appeared to be dismissive and contemptuous when the emotional intensity of the interactions between group members became too heated. She became able to identify this withdrawal as a way of managing fleeting feelings of anxiety, inadequacy and self-consciousness when others spoke about their relationships: she had been coping only by telling herself that she was not as disturbed as the other group members and that it was a waste of time being in the group.

\section{Schema-focused therapy}

Schema-focused therapy is an integrative psychotherapy that expands strategies from traditional cognitive-behavioural therapy, but also systematically incorporates elements from object relations, psychodynamic and gestalt therapeutic models. Originally developed by Jeffrey Young and colleagues in The Netherlands (Young 2003), it is increasingly used in the UK and other countries to treat borderline personality disorder, and there is some evidence from randomised controlled trials for its efficacy in the treatment of that disorder (GiessonBloo 2006). To date, no clinical trials of schemafocused therapy have been conducted for NPD, but clinical reports suggest that it may be effective for the disorder. Schema-focused therapy focuses 
on challenging early maladaptive schemas regarding relationships to self and others and on promoting a healthier 'adult mode' of functioning. The therapist uses a process of 're-parenting', encouraging the patient to better regulate narcissistic fluctuations in emotional reactivity and to develop empathy for and achieve emotional intimacy with others.

\section{Dialectical behaviour therapy}

Dialectical behaviour therapy is a manualised treatment developed by Marsha Linehan (1993) in the USA, again originally for borderline personality disorder, for which there is evidence of efficacy in randomised controlled trials. It combines individual and group therapy sessions and incorporates cognitive-behavioural principles with acceptance and mindfulness-based skills originating in Buddhist philosophy. Group skills-training sessions are used to promote mindfulness, emotion regulation, distress tolerance and interpersonal effectiveness. It has been used with some patients with symptoms of NPD (Reed-Knight 2011), with whom validation is a key technique to reduce the feelings of shame and self-criticism common in the disorder (Box 6).

\section{Meta-cognitive interpersonal therapy}

Meta-cognitive interpersonal therapy for NPD is a manualised step-by-step treatment developed in Italy by Giancarlo Dimaggio and colleagues (Dimaggio 2012) and particularly focusing on perfectionism. It is aimed at dismantling narcissistic processes, with shared understanding of the patient's problems in their autobiographical context, progressing to recognition of maladaptive schemas and interpersonal functioning, and finally to promoting change through identification of grandiosity, distancing from old behaviour, reality- and perspective-taking and building more healthy schemas

\section{Conclusions}

Historically, research activity into the nature and treatment of problematic narcissistic personality traits, pathological narcissism and NPD has been much greater in the USA and, to some degree, in other European countries, particularly Italy, than in the UK. Similarly, a formal diagnosis of NPD is less frequently made by psychiatrists in the UK, and the specific treatment modalities adapted for this disorder are generally less available here than in the USA. This apparent lack of interest in the disorder in the UK may in part be because ICD-10 (World Health Organization 1992), which does not list NPD as a recognised specific personality disorder, is used as the official diagnostic classification system for mental disorders in this country, rather than DSM-5.

Nevertheless, regardless of whether a formal DSM diagnosis of NPD is made, psychiatrists should be alert to the presence of narcissistic pathology in their patients, as it may significantly influence their management and treatment within mental health services. Moreover, personality disorder services are increasingly offering a range of evidence-based psychological interventions, and although for the most part these are not specifically targeted at people with NPD, the adaptations and innovations in therapeutic technique that are being developed by specialists in the field should be of interest to any clinician involved in treating this difficult patient population.

Work with these individuals highlights the fine balance between healthy and pathological narcissism, the problems of desire and dependency, and the challenges in accepting human limitation, vulnerability and need that exist in all of us. All clinicians should strive for compassion towards patients at risk of re-enacting the story of Narcissus, who turned away from life and love towards the death of Echo and himself in the ultimate narcissistic act.

\section{References}

Adorno T (1968) Sociology and psychology. New Left Review, 47: 67-80.

American Psychiatric Association (1980) Diagnostic and Statistical Manual of Mental Disorders (3rd edn) (DSM-III). American Psychiatric Association.

American Psychiatric Association (1987) Diagnostic and Statistical Manual of Mental Disorders (3rd edn revised) (DSM-III-R). American Psychiatric Association.

American Psychiatric Association (1994) Diagnostic and Statistical Manual of Mental Disorders (4th edn) (DSM-IV). APA.

American Psychiatric Association (2013) Diagnostic and Statistical Manual of Mental Disorders (5th edn) (DSM-5). American Psychiatric Publishing.

Bakermans-Kranenburg MJ, van IJzendoorn MH (2009) The first 10,000 Adult Attachment Interviews: distributions of adult attachment representations in non-clinical and clinical groups. Attachment \& Human Development, 11: 223-63.

Bateman A (1998) Thick- and thin-skinned organisations and enactment in borderline and narcissistic disorders. International Journal of PsychoAnalysis, 79: 13-25.

Bateman AW, Fonagy P (eds) (2012) Handbook of Mentalizing in Mental Health Practice. American Psychiatric Publishing.

Beck AT, Freeman A, et al (1990) Cognitive Therapy of Personality Disorders. Guilford Press

Britton R (2003) Sex, Death and the Superego: Experiences in Psychoanalysis. Karnac Books.

Cain NM, Pincus AL, Ansell EB (2008) Narcissism at the crossroads: phenotypic description of pathological narcissism across clinical theory, social/personality psychology, and psychiatric diagnosis. Clinical Psychology Review, 28: 638-56.

Cherrier JF (2013) Reflections on mentalization-based treatment and its adaptation for men presenting a narcissistic personality disorder and a 
not otherwise specified personality disorder. Santé Mentale au Québec, 38: 243-58.

Clarkin JF, Yeomans FE, Kernberg OF (2006) Psychotherapy for Borderline Personality: Focusing on Object Relations. American Psychiatric Association.

Clarkin JF, Levy KN, Lenzwenger MF, et al (2007) Evaluating three treatments for borderline personality disorder: a multiwave study. American Journal of Psychiatry, 164: 1-8.

Cleckley H (1941) The Mask of Sanity: An Attempt to Clarify Some Issues about the So-Called Psychopathic Personality. C V Mosby.

Cukrowicz KC, Poindexter EK, Joiner Jr TE (2011) Cognitive behavioural approaches to the treatment of narcissistic personality disorder. In The Handbook of Narcissism and Narcissistic Personality Disorder: Theoretical Approaches, Empirical Findings, and Treatments (eds WK Campbell, JD Miller): 457-65. John Wiley \& Sons.

Dhawan N, Kunik ME, Oldham J, et al (2010) Prevalence and treatment of narcissistic personality disorder in the community: a systematic review. Comprehensive Psychiatry, 51: 333-9.

Diamond D, Levy KN, Clarkin JF, et al (2014) Attachment and mentalization in female patients with comorbid narcissistic and borderline personality disorder. Personality Disorders: Theory, Research and Treatment, 5 428-33.

Dickinson KA, Pincus AL (2003) Interpersonal analysis of grandiose and vulnerable narcissism. Journal of Personality Disorders, 17: 188-207.

Dimaggio G, Attinà G (2012) Metacognitive interpersonal therapy for narcissistic personality disorders with perfectionistic features: the case of Leonardo. Journal of Clinical Psychology, 68: 922-34.

Ellis H (1898) Auto-eroticism: a psychological study. Alienist and Neurologist, 19: 260-99.

Esse E (2008) The Adult Attachment Interview. Protocol, Method of Analysis, and Empirical Studies. In Handbook of Attachment. Theory, Research, and Clinical Applications (eds J Cassidy, PR Shaver): 552-598. The Guilford Press.

Fossati A, Feeney J, Pincus A, et al (2014) The structure of pathologica narcissism and its relationships with adult attachment styles: a study of Italian nonclinical and clinical adult participants. Psychoanalytic Psychology, 32: 1-29.

Foster JD, Campbell WK, Twenge JM (2003) Individual differences in narcissism: inflated self views across the lifespan and around the world. Journal of Research in Personality, 37: 469-86.

Freud S (1914) On narcissism. In The Standard Edition of the Complete Psychological Works of Sigmund Freud (vol 14) (ed J Strachey): 67-102. Hogarth Press.

Giesson-Bloo J, van Dyck R, Spinhoven P, et al (2006) Randomised trial of schema focused therapy $v$. transference focused therapy. Archives of General Psychiatry, 63: 649-58.

Hare R (2003) Hare Psychopathy Checklist-Revised (PCL-R): 2nd edition Technical Manual. Multi Health Systems.

Hasin DS, Grant BF (2015) The National Epidemiologic Survey on Alcohol and Related Conditions (NESARC) Waves 1 and 2: review and summary of findings. Social Psychiatry and Psychiatric Epidemiology, 50: 1609-40.

Horney K (1939) New Ways in Psychoanalysis. Horton.

Horton SH (2011) Parenting as a cause of narcissism: empirical support for psychodynamic and social learning theories. In The Handbook of Narcissism and Narcissistic Personality Disorder: Theoretical Approaches, Empirical Findings, and Treatments (eds WK Campbell, JD Miller): 181-90. John Wiley \& Sons.

Jenkins R, Bebbington P, Buhgra D, et al (2003) British psychiatric morbidity survey. International Review of Psychiatry, 15: 14-8.

Katerud S, Wilberg T (2007) From general day hospital treatment to specialised treatment programmes. International Review of Psychiatry, 19: 39-49.

Kernberg OF (1984) Severe Personality Disorders: Psychotherapeutic Strategies. Yale University Press.

Kernberg OF (1992) Aggression in Personality Disorders and Perversions. Yale University Press.
Klein M (1946) Notes on some schizoid mechanisms. In Envy and Gratitude and Other Works (ed M Klein): 1-24. Hogarth

Kohut H (1971) The Analysis of the Self: A Systematic Approach to the Psychoanalytic Treatment of Narcissistic Personality Disorders. International Universities Press.

Lasch C (1979) The Culture of Narcissism: American Life in an Age of Diminishing Expectations. Warner Books.

Lee T, Mach E, Grove P (2013) Complexities in narcissistic personality disorder assessment, engagement and treatment. Presentation at the Roya College of Psychiatrists' Faculty of Medical Psychotherapy Annual Conference, 17-19 April 2013 (https://www.rcpsych.ac.uk/pdf/calcmpcon2013tennysonleeewamach.pdf).

Levy KN, Ellison WD, Reynoso JS (2011) A historical view of narcissism and narcissistic personality disorder. In The Handbook of Narcissism and Narcissistic Personality Disorder: Theoretical Approaches, Empirical Findings, and Treatments (eds WK Campbell, JD Miller): 3-13. John Wiley \& Sons

Linehan MM (1993) Cognitive Behavioural Treatment of Borderline Personality Disorder. Guilford Press.

Livesley WJ (2012) Integrated treatment: a conceptual framework for an evidence-based approach to the treatment of personality disorder. Journal of Personality Disorders, 26: 17-42.

Meyers B, Pilkonis P A (2011) Attachment theory and narcissistic personality disorder. In The Handbook of Narcissism and Narcissistic Personality Disorder: Theoretical Approaches, Empirical Findings, and Treatments (eds WK Campbell, JD Miller): 434-444. John Wiley \& Sons.

Miles GJ, Francis AJ (2014) Narcissism: is parenting style to blame, or is there X-chromosome involvement? Psychiatry Research, 219: 712-3.

Miller JD, Dir A, Gentile B, et al (2010) Searching for a vulnerable dark triad: comparing factor 2 psychopathy, vulnerable narcissism, and borderline personality disorder. Journal of Personality, 78: 1529-64.

Millon T (1981) Disorders of Personality. John Wiley \& Sons.

Oquendo MA (2016) The Goldwater Rule: why breaking it is unethical and irresponsible [blog]. American Psychiatric Association (https://www.psychiatry.org/news-room/apa-blogs/apa-blog/2016/08/the-goldwater-rule).

Otway LJ, Vignoles VL (2006) Narcissism and childhood recollections: a quantitative test of psychoanalytic predictions. Personality and Social Psychology Bulletin, 32: 104-16.

Pincus AL, Lukowitsky MR (2010) Pathological narcissism and narcissistic personality disorder. Annual Review of Clinical Psychology. 68: 943-953. Pincus AL, Cain NM, Wright AG (2014) Narcissistic grandiosity and narcissistic vulnerability in psychotherapy. Personality Disorders: Theory, Research and Treatment, 5: 439-43.

Rank 0 (1911) A contribution to narcissism. Jarhbuch für Psychoanalytische und Psychopathlogische Forshungen, 3: 401-26.

Raskin RN, Hall CS (1979) A narcissistic personality inventory. Psychological Reports, 45: 590.

Reed-Knight B, Fischer S (2011) Treatment of narcissistic personality disorder symptoms in a dialectical behaviour therapy framework: a discussion and case example. In The Handbook of Narcissism and Narcissistic Personality Disorder: Theoretical Approaches, Empirical Findings, and Treatments (eds WK Campbell, JD Miller): 466-75. John Wiley \& Sons.

Reich W (1933) Charakteranalyse. Reprinted (1949) as Character Analysis (3rd edn) (trans VR Carfagno). Farrar, Straus and Giroux.

Ronningstam E (1996) Pathological narcissism and narcissistic personality disorder in Axis I disorders. Harvard Review of Psyhciatry, 3: 326-40.

Ronningstam EF (2014) Narcissistic personality disorder. In Gabbard's Treatments of Psychiatric Disorders (ed GO Gabbard): 1073-86. American Psychiatric Publishing

Rosenfeld H (1987) Impasse and Interpretation. Tavistock.

Rosenstein DS, Horowitz HA (1996) Adolescent attachment and psychopathology. Journal of Consulting and Clinical Psychology, 64: 244-53.

Rossouw TI (2015) The use of mentalization-based treatment for adolescents (MBT-A) with a young woman with mixed personality disorder and tendencies to self-harm. Journal of Clinical Psychology, 71: 178-87. 
Seligman S (2007) Mentalization and metaphor, acknowledgment and grief: forms of transformation in the reflective space. Psychoanalytic Dialogues, 17: 321-44.

Smolewska K, Dion K (2005) Narcissism and adult attachment: a multivariate approach. Self and Identity, 4: 59-68.

Skodol EA, Bender DS, Morey LC (2014) Narcissistic personality disorder in DSM-5. Personality Disorders: Theory, Research and Treatment, 5: 422-7.

Stinson FS, Dawson DA, Goldstein RB, et al (2008) Prevalence, correlates, disability, and comorbidity of DSM-IV narcissistic personality disorder: results from the Wave 2 National Epidemiologic Survey on Alcohol and Related Conditions. Journal of Clinical Psychiatry, 69: 1033-45.

Torgersen S, Czajkowski N, Jacobson K, et al (2008) Dimensional representations of DSM-IV cluster B personality disorders in a populationbased sample of Norwegian twins: a multivariate study. Psychological Medicine, 38: 1617-25.

Twenge JM, Campbell WK (2009) The Narcissism Epidemic: Living in the Age of Entitlement. Free Press.
Widiger TA, Trull TJ (1994) (1998) Performance characteristics of the DSM-III-R personality disorder criteria sets. In DSM-IV Sourcebook (vol 4) (eds A Widiger, AJ Francis, HA Pincus, et al): 357-73). American Psychiatric Press.

Winnicott DW (1960) Ego distortion in terms of true and false self. Reprinted (2018) In The Maturational Processes and the Facilitating Environment (DW Winnicott): 140-52. Routledge.

Wolfe T (1976) The "me" decade and the third great awakening. New York Magazine, 23 August: 26-40.

World Health Organization (1992) The ICD-10 Classification of Mental and Behavioural Disorders: Clinical Descriptions and Diagnostic Guidelines. WHO.

Young JE, Klosko JS, Weishaar ME (2003) Schema Therapy: A Practitioner's Guide. Guilford.

Zimmerman M, Rothschild L, Chelminski I (2005) The prevalence of DSMIV personality disorders in psychiatric outpatients. American Journal of Psychiatry, 162: 1911-8.
MCOs

Select the single best option for each question stem

1 Regarding the concept of narcissism:

a Freud was the first to conceptualise narcissism as a clinical entity

b Freud, Rank and Winnicott all conceptualised narcissism as a dimensional psychological state that ranged from normal to pathological

c Kernberg emphasises conflict and aggression in the development of pathological narcissism

d social-personality psychology conceptualises narcissism as a maladaptive personality trait

e Millon's social learning perspective proposes that pathological narcissism results from early parental neglect.

2 The DSM- 5 diagnosis of NPD:

a is weighted towards the vulnerable aspects of the disorder

$\mathrm{b}$ is modelled on a dimensional/categorical hybrid

c is usually welcomed by the patient in providing a legitimate diagnosis of their difficulties $\mathrm{d}$ is unchanged from DSM-IV

$\mathrm{e}$ is best measured by the Narcissistic Personality Inventory.

3 In the epidemiology of NPD:

a studies consistently report a prevalence in nonclinical samples of $1-3 \%$

b the most frequent DSM-5 personality disorders comorbid with NPD are borderline personality disorder and histrionic personality disorder

c NPD is more common in older White men

d comorbidity between bipolar affective disorder and NPD suggests that both disorders may share underlying aetiological factors

e empirical studies have reported that the prevalence of NPD is greater in the USA than in the UK.

4 Regarding the aetiology of NPD:

a genetic factors are unlikely to have an influence in the development of NPD b patients with NPD whose presentation is characterised by prominent grandiosity are more likely to have dismissing attachment patterns as measured on the Adult Attachment Interview

c studies show that parental coldness is consistently associated with both grandiose narcissism and vulnerable narcissism

d Kernberg suggests that a failure of parental empathy is a main contributor to the development of NPD

e sibling rivalry is likely to be a contributory factor.

5 In the management and treatment of NPD:

a individual therapy is the treatment of choice

b cognitive behavioural therapy has been shown to have superior efficacy to other modalities

c the patient may simulate therapeutic progress

$d$ the patient is best treated by an experienced clinician

e patients with more prominent symptoms of low self-worth are less likely to drop out of therapy. 